Marquette University

e-Publications@Marquette

Economics Faculty Research and Publications

Economics, Department of

$10-1-1990$

\title{
The Slowdown in Soviet Defense Expenditures: Comment
}

\author{
Abdur Chowdhury \\ Marquette University, abdur.chowdhury@marquette.edu \\ Josef C. Brada \\ Ronald L. Graves
}

Published version. Southern Economic Journal, Vol. 57, No. 2 (October 1990): 533-537. DOI. (C) 1990 Southern Economic Association. Used with permission. 


\section{The Slowdown in Soviet Defense Expenditures: Comment*}

\section{Introduction}

In a recent article in this Journal, Brada and Graves [2] attempt to explain the reasons for the slowdown in Soviet defense expenditures in the mid-1970s. They argue that Soviet defense expenditures, measured by a low and a high estimate (SDL and $S D H$ respectively), depend on Soviet GNP, the level of U.S. defense spending and the strategic balance between the two countries. Moreover, their results indicate that in mid-1970s a structural break occurred in the regression regime explaining Soviet defense outlays. On the basis of these results, they derive two apparently different conclusions. In case of $S D L$, they argue that " . . . the slowdown in Soviet defense expenditures is partly due to economic factors and partly due to a change in Soviet behavior which caused a ceteris paribus decline in defense outlays" [2, 982]. On the other hand, for $S D H$ their results indicate that ". . . the change in regime actually resulted in higher defense outlays than would have occurred under the pre-break regime" $[2,982-3]$.

The aim of this note is to show that the reason for this apparently opposing results is the fact that Brada and Graves's (hereinafter BG) paper suffers from a serious serial correlation problem. The majority of regressions in BG, for example, display Durbin-Watson statistics which reject the null hypothesis of no autocorrelation. Re-estimation of their results, after correcting for serial correlation, changes some of their major conclusions regarding the factors influencing Soviet defense spending. The level of U.S. defense spending and the strategic balance between the U.S. and the Soviet Union no longer exerts any significant influence on Soviet defense outlays. Furthermore, the new corrected results indicate that no structural break occurred in the mid-1970s. Irrespective of the Soviet defense outlay measure employed, the new results are consistent. This has serious policy implication. Contrary to BG's paper, the results suggest that there has been no change in Soviet military doctrine or in the Soviet leadership's preferences in the seventies.

\section{Estimation Results}

On the basis of the Durbin Watson $d$ test, the disturbances of the $S D L$ equation used in BG's paper are positively autocorrelated for all the periods and the disturbances of their $S D H$ equation are positively autocorrelated in about half of the periods. If, in fact, the disturbances are positively autocorrelated, then the usual OLS formulae for the sampling variances of the regression coefficients are likely to give a serious underestimate of these variances. Consequently, the $t$ values would be upward biased. The conventional $t$ test will no longer be valid. ${ }^{1}$

To cope with this problem, the parameters of the BG equations have been reestimated using applies.

*The author would like to thank an anonymous referee for helpful comments and suggestions. The usual caveat

1. For a more detailed explanation of this issue, see Harvey [6]. 
Table I. Coefficient Estimates of Regressions on Low and High Estimates of Soviet Defense Expenditures*

\begin{tabular}{|c|c|c|c|c|c|c|c|c|}
\hline \multirow[b]{2}{*}{ Variable } & \multicolumn{4}{|c|}{ SDL } & \multicolumn{4}{|c|}{ SDH } \\
\hline & Eq. (3) & Eq. $(3)^{\prime}$ & Eq. (4) & Eq. (4)' & Eq. (3) & Eq. $(3)^{\prime}$ & Eq. (4) & Eq. $(4)^{\prime}$ \\
\hline onstant & $\begin{array}{r}-3.860 \\
(5.72)\end{array}$ & $\begin{array}{r}-1.216 \\
(1.86)\end{array}$ & $\begin{array}{c}-4.198 \\
(6.89)\end{array}$ & $\begin{array}{r}-1.334 \\
(2.12)\end{array}$ & $\begin{array}{r}-1.992 \\
(2.81)\end{array}$ & $\begin{array}{c}-2.656 \\
(3.36)\end{array}$ & $\begin{array}{r}-2.357 \\
(3.72)\end{array}$ & $\begin{array}{r}-2.625 \\
(3.34)\end{array}$ \\
\hline USD & $\begin{array}{r}0.174 \\
(2.47)\end{array}$ & $\begin{array}{c}0.046 \\
(0.77)\end{array}$ & $\begin{array}{r}0.230 \\
(3.49)\end{array}$ & $\begin{array}{r}0.057 \\
(0.98)\end{array}$ & $\begin{array}{c}0.056 \\
(0.76)\end{array}$ & $\begin{array}{r}0.104 \\
(1.20)\end{array}$ & $\begin{array}{r}0.116 \\
(1.69)\end{array}$ & $\begin{array}{l}0.108 \\
(1.25)\end{array}$ \\
\hline$S Y$ & $\begin{array}{r}1.124 \\
(18.24)\end{array}$ & $\begin{array}{r}0.813 \\
(11.93)\end{array}$ & $\begin{array}{r}1.130 \\
(20.74)\end{array}$ & $\begin{array}{r}0.822 \\
(12.65)\end{array}$ & $\begin{array}{r}0.969 \\
(14.98)\end{array}$ & $\begin{array}{r}1.034 \\
(13.14)\end{array}$ & $\begin{array}{r}0.975 \\
(17.22)\end{array}$ & $\begin{array}{r}1.026 \\
(13.29)\end{array}$ \\
\hline$S F P$ & & & $\begin{array}{r}-0.024 \\
(2.64)\end{array}$ & $\begin{array}{r}-0.007 \\
(1.46)\end{array}$ & & & $\begin{array}{r}-0.025 \\
(2.73)\end{array}$ & $\begin{array}{c}-0.006 \\
(0.94)\end{array}$ \\
\hline$S P$ & $\begin{array}{r}-0.037 \\
(1.22)\end{array}$ & $\begin{array}{c}0.043 \\
(1.77)\end{array}$ & $\begin{array}{r}-0.069 \\
(2.35)\end{array}$ & $\begin{array}{r}0.037 \\
(1.56)\end{array}$ & $\begin{array}{r}0.057 \\
(1.80)\end{array}$ & $\begin{array}{r}0.031 \\
(0.92)\end{array}$ & $\begin{array}{c}0.023 \\
(0.74)\end{array}$ & $\begin{array}{l}0.030 \\
(0.88)\end{array}$ \\
\hline \multicolumn{9}{|c|}{ Summary Statistics } \\
\hline $\bar{R}^{2}$ & 0.980 & 0.947 & 0.985 & 0.954 & 0.979 & 0.988 & 0.984 & 0.988 \\
\hline S.E.E. & 0.0427 & 0.0207 & 0.0377 & 0.0201 & 0.0448 & 0.0296 & 0.0392 & 0.02 \\
\hline D.W. Statistics & 0.696 & 1.377 & 1.240 & 1.460 & 0.487 & 1.314 & 0.998 & 1.412 \\
\hline rho & & $\begin{array}{c}0.628 \\
(3.95)\end{array}$ & & $\begin{array}{c}0.613 \\
(3.80)\end{array}$ & & $\begin{array}{c}0.762 \\
(5.69)\end{array}$ & & $\begin{array}{r}0.715 \\
(5.07)\end{array}$ \\
\hline
\end{tabular}
*Variables:
USD - Natural logarithm of real U.S. defense spending
$S Y$ - Natural logarithm of real Soviet Gross National Product
$S F P$ - Natural logarithm of the growth of factor productivity in Soviet industry
$S P$ - Natural logarithm of the ratio of deliverable Soviet warheads to deliverable U.S. warheads.
The figures in parentheses are the absolute value of the $t$-statistics.

a maximum likelihood estimation procedure which yields parameter estimates that are consistent and asymptotically efficient. ${ }^{2}$ According to their own admission, equations (1) and (2) in their paper are misspecified. So we have concentrated on equations (3) and (4) of their paper.

The new regression results are given in Table $I .{ }^{3}$ The equations have high overall explanatory power as shown by the values of adjusted $R^{2}$. Equations (3) and (4) show the results of our effort to replicate their findings, while the results after correcting for serial correlation are given in equations (3) ${ }^{\prime}$ and (4)' respectively. A comparison of equations (3) and (4)' with equations (3) and (4) respectively will show how the results change after appropriate corrections are made for serial correlation. In case of $S D L$, equations (3)' and (4)' show an improvement over equations (3) and (4) respectively as the S.E.E. decreases significantly. The coefficient estimates in equations (3)' and (4)' show that the U.S. defense expenditures (USD) variable is statistically insignificant. This is in contrast to BG's paper where the $U S D$ variable is statistically significant. Moreover, the value of the elasticity is much lower than those reported in their paper. The Soviet income variable $(S Y)$ maintains its statistical significance in both the equations. The growth of Soviet factor pro-

2. To obtain the parameter estimates, the sum of squared residuals is minimized conditional on the autocorrelation coefficient, which is found using a grid search across the region -1.0 to 1.0 to an accuracy of 0.01 . This approach avoids the possible iteration to a non-global minimum, a possibility using the alternative Cochrane-Orcutt technique.

3. For purposes of comparison, we have tried to replicate their results using their methodology. Unfortunately, we failed to reproduce their results in entirety. For instance, in case of SDL, the D.W. Statistics in equation (3) is about 30 percent lower than those reported in their paper. Moreover, in case of SDH, the coefficient estimates and D.W. Statistics of equation (4) are different in our paper. Our effort to replicate their results are given in equations (3) and (4) in Table I. 
Table II. Results of Chow Tests for Structural Break

\begin{tabular}{llcc}
\hline Dependent Variable & Explanatory Variable & Year of Break & Chow Test \\
\hline$S D L$ & USD, SY, SP & 1976 & 1.484 \\
$S D L$ & USD, SY, SFP, SP & 1976 & 1.706 \\
SDH & USD, SY, SP & 1976 & 0.957 \\
$S D H$ & USD, SY, SFP, SP & 1973 & 2.149 \\
\hline
\end{tabular}

ductivity $(S F P)$ variable in equation (4)' becomes insignificant. This indicates that the slowdown in Soviet industrial productivity had no influence on their defense outlays. Finally, the strategic parity $(S P)$ variable changes sign in the new equation. Contrary to BG's findings, this implies that Soviet Union increases defense spending as its number of nuclear weapons increase relative to the United States. Such behavior suggests a more competitive policy on the part of the Soviet Government than is envisaged in BG's paper.

In case of $S D H$, the new regressions $\left[(3)^{\prime}\right.$ and $\left.(4)^{\prime}\right]$ again exhibit a lower value of S.E.E. than equations (3) and (4) respectively. ${ }^{4}$ The U.S. defense expenditures is again statistically insignificant while the Soviet income variable maintains its statistical significance. Contrary to their findings, the strategic parity variable $(S P)$ in equation $(3)^{\prime}$ and the Soviet factor productivity variable $(S F P)$ in equation (4)' become insignificant. The results thus indicate that Soviet defense spending is responsive only to Soviet GNP. Irrespective of the Soviet defense outlay measure employed, the results consistently show that changes in U.S. defense spending do not significantly affect Soviet defense expenditures.

In order to test for the hypothesis of a structural break in the regression regime explaining Soviet defense expenditures in the mid-1970s, two different stability tests are performed. The first test is due to Chow [4]. He proposes a test for a change in one or more coefficients between one part of the sample and the rest. This test is powerful in detecting a discrete jump that takes place at the point where the sample is partitioned. Chow tests are conducted to determine whether the coefficients for the pre-break period are significantly different from those of the post-break period. One unfortunate feature of this test is the necessity to specify, a priori, the break in the relationship being examined. ${ }^{5}$ As an alternative, a Stabilogram test, due to Ashley [1], is performed to detect parameter instability during the sample period without making any assumption about the form that it may take. This test, an extension of the Chow test, allows detection of the discrete jump and also provides insight into which parameter(s) is (are) responsible for the jump. This test is a straightforward application of covariance analysis and makes use of zero-one dummy variables. ${ }^{6}$ The results of the Chow tests are given in Table II while Table III reports the results of the Stabilogram tests.

4. It should be noted that the decrease in S.E.E. in equation (4)' is marginal.

5. Further, the limitations of Chow test in the presence of heteroscedasticity is well-known. However, Lagrange Multiplier tests for the equations in Table I showed the absence of heteroscedasticity in the residuals.

6. The basis of the Stabilogram test dates back to Gujarati [5]. This test, rather than the recursive residual procedure of Brown-Durbin-Evans [3] or Harvey [6], is employed since both the Brown-Durbin-Evans and the Harvey tests inherently consider the stability of all coefficients. In contrast, the Stabilogram test can be used to focus on a subset of the coefficients whose stability may be either in great doubt or of more immediate interest. Monte Carlo simulations by Ashley [1] indicate that the Stabilogram test is exact, in the statistical sense, and simple to use. Moreover, the nominal power of the test is comparable to that of more sophisticated alternatives. To conserve space, a description of the test is not included here. Interested readers are referred to Ashley [1] for a theoretical description and Himarios [7], among others, for an empirical application. 
Table III. Stabilogram Test Results on Various Coefficients for Sample Period 1960-84*

\begin{tabular}{lcccr}
\hline Equation & Coefficient & RSS & URSS & $F$-Statistics \\
\hline$S D L, U S D, S Y, S P$ & USD & 0.00854 & 0.00599 & $F(4,17)=1.80$ \\
& $S Y$ & 0.00854 & 0.00517 & $=2.78$ \\
& $S P$ & 0.00854 & 0.00527 & $=2.64$ \\
$S D L, U S D, S Y, S F P, S P$ & $U S D$ & 0.00770 & 0.00622 & $F(4,16)=0.95$ \\
& $S Y$ & 0.00770 & 0.00607 & $=1.07$ \\
& $S F P$ & 0.00770 & 0.00498 & $=2.18$ \\
& $S P$ & 0.00770 & 0.00538 & $=1.72$ \\
$S D H, U S D, S Y, S P$ & $U S D$ & 0.01840 & 0.01383 & $F(4,17)=1.40$ \\
& $S Y$ & 0.01840 & 0.01317 & $=1.69$ \\
$S D H, U S D, S Y, S F P, S P$ & $S P$ & 0.01840 & 0.01326 & $=1.65$ \\
& USD & 0.01771 & 0.01335 & $F(4,16)=1.31$ \\
& $S Y$ & 0.01771 & 0.01438 & $=0.93$ \\
& $S F P$ & 0.01771 & 0.01325 & $=1.35$ \\
& $S P$ & 0.01771 & 0.01251 & $=1.43$ \\
\hline
\end{tabular}

${ }^{*} \mathrm{RSS}=$ Sum of squared residuals from the original equation

URSS $=$ Sum of squared residuals from the partitioned equation

For the methodology for calculating the $F$-statistics, see Ashley $[1,258]$.

BG claims that a structural shift occurred in the SDL equation in 1976 while the $S D H$ equation experienced a structural shift in 1976 [equation (3)] and 1973 [equation (4)] respectively. Hence they argue that the data over the entire sample period cannot be pooled. Their conclusions are based on Tables VI and VII in their paper where the coefficients appear to be different for the sub-sample periods. We use equations (3)' and (4)' and the break-points used in BG's paper to conduct Chow test. The relevant $F$-statistics are reported in Table II. Irrespective of the dependent variable or the break-point employed, the value of the $F$-statistics do not provide enough evidence to reject the hypothesis of stability?

The results of the Stabilogram tests are given in Table III. None of the $F$-statistics of the Stabilogram test is significant at the 5 percent significance level. So the null hypothesis of stable coefficients cannot be rejected. The apparently differing estimates reported by BG in their Tables VI and VII may be the result of multicollinearity among the regressors due to the small number of degrees of freedom available in each sub-sample. ${ }^{8}$

\section{Conclusion}

Hence, the findings of this paper contradict two major conclusions of BG's paper. First, the results indicate that no structural change has taken place in mid-1970s in Soviet policy-making or in the leadership's perceptions of Soviet defense needs. Second, U.S. defense spending appears to exert little, if any, influence on Soviet defense outlays. It should, however, be noted that the Table II.

7. The Chow test have also been performed for the mid-point (1972). The results are similar to those reported in

8. For a further discussion of this issue, see Maddala [8, 199]. This has also been pointed out in Himarios [7]. 
results of this as well as BG's study may be viewed as suggestive, since one should be extremely cautious about interpreting any regression estimates based on about 20 degrees of freedom.

\author{
Abdur R. Chowdhury \\ Marquette University \\ Milwaukee, Wisconsin
}

\title{
References
}

1. Ashley, Richard, "A Simple Test for Regression Parameter Instability." Economic Inquiry, April 1984, 253-68.

2. Brada, Josef and Ronald L. Graves, "The Slowdown in Soviet Defense Expenditures." Southern Economic Journal, April 1988, 969-83.

3. Brown, R. L., J. Durbin, and J. M. Evans, "Techniques for Testing the Constancy of Regression Relationships Over Time, with Comments." Journal of Royal Statistical Society, Series B, 1975, 149-92.

4. Chow, Gregory, "Tests of Equality Between Subsets of Coefficients in Two Linear Regressions." Econometrica, July $1960,591-605$.

5. Gujarati, Damodar, "Use of Dummy Variables in Testing for Equality Between Sets of Coefficients in Two Linear Regressions." American Statistician, February 1970, 50-52.

6. Harvey, A. C., "An Alternative Proof and Generalization of a Test for Structural Change." The American Statistician, April 1976, 122-23.

7. Himarios, Daniel, "Has There Been a Shift in the Greek Money Demand Function?" Kredit and Kapital, April, $1987,106-15$.

8. Maddala, G. S. Econometrics. New York: McGraw-Hill, 1977. 